OMEGA, Vol. 64(3) 185-202, 2011-2012

\title{
THROUGH THE TOUCH OF GOD: CHILD DEATH AND SPIRITUAL SUSTENANCE IN A HUTTERIAN COLONY
}

\author{
JOANNE CACCIATORE, PHD, FT, LMSW \\ REBECCA ONG, MSW
}

Arizona State University, Phoenix

\begin{abstract}
Nestled in more than 5,000 acres of farmland in rural South Dakota, one Hutterian colony flourishes with more than 23 families and a population of 115 people. Very little is known about the ways in which Hutterites experience traumatic infant and child death on the colony. No research studies to date have explored this topic. This is an ethnographic study that utilized extended observations of the group and both individual and group interviewing in order to create a cultural portrait specifically focusing on Hutterites experiencing traumatic child death. Observations were organized into five thematic categories: 1) details of the actual death experience; 2) emotional and physical reactions to the loss; 3) familial and communal response; 4) coping and rituals; and 5) spirituality. The role of communal mourning, ritualization, and spirituality in creating a healing milieu for bereaved families is discussed.
\end{abstract}

\section{GENERAL ETHNOGRAPHIC BACKGROUND}

\section{History}

The Hutterites, like the Mennonites, the Amish, and the Brethren in Christ, had their beginnings during the Reformation in the 16th century as a part of the

(c) 2011, Baywood Publishing Co., Inc.

doi: 10.2190/OM.64.3.a

http://baywood.com 
Anabaptist movement, whose core beliefs include adult baptism and pacifism. In 1528, a group of Anabaptist refugees, fleeing persecution in Austria and led by Jacob Wiedemann and Philip Jager, established an assembly of 200 people under a communal ownership of property, or a "full community of goods," in Moravia in the present-day Czech Republic. In time, members of this Moravian assembly and other Anabaptist refugees organized into a church led by Jacob Hutter, from whom the group took their name.

Following a "Golden Period" of expansion and economic prosperity in the mid-to-late $1500 \mathrm{~s}$, a succession of wars and religious persecution caused the Hutterites to abandon communal life on several occasions and move further east to Slovakia, Hungary, and present-day Romania, seeking safety and religious freedom. Bruderhöfe, or colonies, established in Russia in the Ukraine renewed the practice of communal living and community of goods under the leadership of Michael Waldner in 1859. In the 1870s, following the passage of a Russian law making military service compulsory, the Hutterites emigrated to North America, where today there are approximately 45,000 Hutterites living in over 450 colonies (Hofer, 1998; Hutterian Brethren Schmiedeleut Conference, 2006; Janzen, 2005; Packull, 1999; Rhodes, 2009).

\section{Social Structure}

At first glance, a Hutterian colony appears to be a contradiction. Their faith, values, manner of dress, and language have been maintained for centuries despite persecution and through mass migration. Yet this reverence for history and tradition is juxtaposed with a business acumen equal to that of a modern capitalist business and a willingness to embrace the most modern agricultural technology.

The Hutterites have three distinct subgroups, or "Leut," which were established around the time of emigration from the Ukraine to North America: Schmiedeleut, Dariusleut, and Lehrerleut. These three groups share a common belief system, each is its own denomination with its own unique culture and discipline. The Schmiedeleut are named after their leader Michael Waldner, a blacksmith (schmied) and preacher; the Dariusleut, after minister Darius Walter; and the Lehrerleut, after their leader Jakob Wipf, who was a teacher (Lehrer). The Schmiedeleut live primarily in North and South Dakota, Minnesota, and Manitoba, while the Dariusleut and Lehrerleut colonies are located mainly in Alberta, Saskatchewan, Montana, and the state of Washington (Hofer, 1998). A fourth subgroup, known as the Prairieleut, are the descendants of the Hutterites who emigrated from the Ukraine but established privately-held homesteads and individual Hutterite congregations that were eventually absorbed into Mennonite and other communities. In 1992, the Schmiedeleut were divided into two separate groups, the "progressives," also known as the Hutterian Brethren, led by Jacob Kleinsasser, and the "traditionalists" or "Committee Hutterites," because they function without the leadership of a single elder (Hofer, 1998; Janzen, 2005). 
The hierarchy of the Hutterian community is based on a literal interpretation of the Bible, in which the order of relationships places the community authority over the individual, older people over younger people, and men over women (Janzen \& Stanton, 2010). Each Hutterian Leut is led by a senior male elder called a vorsteher, or preacher, who is responsible for the spiritual leadership of all the Leut's colonies and its members. At the colony level, authority is based on a male hierarchy of economic and spiritual responsibilities. A preacher and assistant preacher work closely with an elected council of five or six men who hold key administrative positions in the colony, such as financial manager, field manager, and the German schoolteacher. Other elected posts include department manager positions, such as the head mechanic, cattle boss, and lead carpenter. Only the congregation's baptized men, collectively known as the brethren, are able to vote on colony decisions and elect leaders. Unbaptized men, like all the women, have no official authority in the colony, although they may exert informal influence (Hofer, 1998; Janzen \& Stanton, 2010; Peter, 1987).

A colony's population can range from 60 to 160 individuals, with the average being about 90 people or 15 families. The labor force of the colony is organized according to gender and age and, in particular, gender roles are clearly proscribed and never challenged. Men are responsible for farm operations, manufacturing, and carpentry, while women perform the domestic work, such as cooking, baking, and sewing. Teenagers and children are assigned chores as appropriate to assist their elders (Hofer, 1998; Janzen \& Stanton, 2010). While a colony is not completely self-sufficient, the community is able to supply much of its own food, furniture, repairs, and clothes through the skilled labor of its members.

The physical size of a Hutterian colony depends on its location and the type of crops and industry in which it is engaged, but can range in size from 5,000 to 20,000 acres. The Hutterites are successful farmers who are particularly known for their large-scale poultry and livestock production, where they have adopted the use of the most modern equipment available. Despite their centuries-old traditions, the Hutterites believe that new technologies can be embraced so long as the entire colony benefits and full community of goods is maintained (Hofer, 1998). In general, animal barns, machine shops, grain storage, and other farm buildings are located on the periphery of the colony, offering more privacy to the church building, schoolhouse, dining hall, communal kitchen, and homes located at its heart. Janzen and Stanton (2010) point out that the Hutterian kitchen and dining hall are "the functional center of every colony ... where important information is exchanged" (p. 202). Meals are prepared by the colony women and eaten communally, with men and women dining separately.

\section{Spirituality}

Faith in God is the centerpiece of Hutterian life, and their Christian beliefs are woven into every aspect of their daily lives. The watershed principles of 
communal living, shared property, and collective ideologies are laid out in the Hutterites' confession of faith, the Ordnungen (church rules), Lehren (sermons), and Lieder (hymns). One Hutterian sermon proclaims, "Just as wine is made of many grapes, pressed, crushed, joined, and merged together in one pure liquid, so also we have been called together from many peoples with many opinions" (Janzen \& Stanton, 2010, p. 76). Hutterian spirituality is expressed through their untiring and cooperative work ethic predicated in humility and honesty, as well as formally through daily worship.

Formal Hutterian worship has two formats: the Gebet, a service that takes place daily before the evening meal, and the Lehr, the longer service that occurs on Sunday mornings. Seating is arranged according to gender and age, with men and women separated and children toward the front. All services include devotional singing, hymns, and a sermon delivered in High German. Most sermons were written by their forefathers and date back to the 16th and 17th centuries. These are still in use today (Hofer, 1998; Janzen \& Stanton, 2010).

\section{Family Life}

The Hutterian definition of family is influenced by their tradition of communal living. In a sense, an entire Hutterite Leut is seen as a large extended family, and this perception is especially true for each specific colony. It is common for a Hutterite man's father, sons, and uncles to live at the same colony for most of their lives, since Hutterite women relocate to their husbands' colonies after marriage (Hofer, 1998; Janzen \& Stanton, 2010).

Each nuclear family lives in its own separate home or apartment, furnished by the community. Despite claims from outsiders of the patriarchal nature of Hutterian society, husbands and wives work together as partners in raising children. Although men and women are separated during the most of the work day and at meals, time is set aside in the evenings and on weekends for families to spend time together. The Hutterites cherish both male and female children and tend to have larger families compared to mainstream society (Hofer, 1998; Janzen \& Stanton, 2010; Peter, 1987; Stahl, 2003).

In addition to their close relationships with their parents, Hutterite children are also nurtured and disciplined by other adults and older children in the colony. For example, new Hutterite mothers typically take 6-week maternity leaves to bond with their newborns before returning to their regular colony duties. At that time, childcare may be provided by the sorgela (young female childcare providers), who are chosen to serve the colony on the basis of age, character, and trustworthiness. According to Janzen and Stanton (2010), the relationship between the sorgela and child is often remembered for life. Additionally, elder men and women in the colony may assist in childcare and adopt the role of "grandpa" and "grandma," regardless of blood relation. In this way, the Hutterites have a broad interpretation of family that sustains and bolsters their communal ties. 


\section{Birth and Death in the Hutterian Colony}

According to Larsen and Vaupel (1993), the Hutterian mortality rate is comparable to that of the U.S. average. The Hutterites' fertility rate is noted to be exceptionally high, with families having a median number of 10 children in the 1950s. However, in recent years, young Hutterite men and women are both delaying marriage by 3 to 4 years and having fewer children, usually less than 6 or 7, as compared to 50 years ago (Janzen \& Stanton, 2010; Morgan, 1983).

Most Hutterites do not fear death. Rather, physical death is viewed as the beginning of a new existence, and the general perception is that those who have tried to live a principled, virtuous, and spiritual life are reasonably assured a place in heaven (Janzen \& Stanton, 2010). The "ideal" death, as summarized by one Hutterite, is a prolonged death, not a sudden death. In his words, "[the Hutterites] want to have plenty of time to consider eternity and to confess and make everything right. We don't like to see a grownup go suddenly" (Hostetler, 1974, p. 248). There is a dearth of literature on Hutterian perceptions of and reactions to infant and child death, and the little that exists merely mentions the topic in passing. For example, in comparison to the death of adults, Stephenson (1983) observed that "Hutterites prize the deaths of children while we [nonHutterites] abhor them" (p. 129). In sum, based on a thorough review of the literature, no cultural portrait exists on the ways in which this unique culturesharing group experiences the deaths of children on the colony.

\section{METHODOLOGY}

\section{Purpose Statement}

This is an ethnographic exploration into the experience of infant and child death on a Midwestern Hutterian colony that will describe, analyze, and interpret observations. This study will incorporate both the emic and the etic to provide a holistic cultural portrait.

\section{Access and Rapport}

According to Bogdan and Biklen (1992), gatekeepers are the key to access and thus researchers have an obligation to provide the following information: Why was the site chosen? How much time will be needed? Will the researcher be intrusive? Where will the results be reported? And, is there reciprocity?

The principal investigator's access to the colony was granted through the farm manager ("boss"), the gatekeeper for this closed system. Initial contact was made through a letter informing the boss of my area of interest, research, and practice. The boss was very interested and invited a telephone conversation that included an extensive discussion about me as an individual, my research agenda, and service within my community for a nonprofit organization that aids parents 
whose children died. Then, mindful to address all five of the suggestions posited above, we discussed the absence of research in this area of colony life, and I described how much time I would need in order to effectively collect data. I explained that I would remain a participant observer, and would minimize disruption to their daily lives. I explained the end result would be a publication in a peer-reviewed journal that would illuminate the culture-sharing group's response to child death on the colony. Finally, to attend to reciprocity, I offered to bring bibliotherapeutic materials specific to parental bereavement to the colony for his perusal in order to disseminate to members. I read the consent form over the phone, and subsequently mailed one to arrive a few weeks prior to my stay at the colony. The boss and I had two more phone conversations beginning in the Spring of 2010, prior to the beginning of the study in June of 2010, and after IRB approval.

As an outsider, I was humble, mindful, and reflexive in my approach with members of the colony (Cacciatore, 2010). Namely, I engaged in active and intentional empathy through facial, vocal, and postural mimicry (Hatfield, Rapson, \& Le, 2010), and in culturally-aware interaction that adopted participants' primary style of communication (Cacciatore, 2009). In addition, I was intentionally willing to engage in therapeutic personal disclosure to build trusting relationships with colony members.

\section{Data Collection}

The holistic perspective is one of circumspect, according to Fetterman (1998), and integrates cultural history, spirituality, politics, economics, and social function. The approach used is realist ethnography, a paradigm often employed by cultural anthropologists, and characterized by Van Maanen (1988) as objective participant observation. Unlike other qualitative methods, the ethnography focuses on hearing the stories of the individual "within the context of their culture and cultural sharing group" (Creswell, 2007, p. 76).

Data collection lasted for 12 days during the summer of 2010. This study utilized five methods of fieldwork to collect data in a systematic order of occurrence:

1. gatekeeper intake;

2. group interviews;

3. individual interviews;

4. key leader interviews; and

5. participant observation.

During the gatekeeper intake, upon arrival at the study site, I met with the boss in his home for approximately 2 hours. We spent several hours talking about our families and building rapport. He provided information specific to this colony

QA:

2 hours--several hours?
QA: Hatfield et al. 2010 or in press and its heritage and culture. Once comfortable with me, he made an announcement 
about the group interview in the church building over the public announcement system. He spoke in German, so I was unable to understand exactly what he said; however, he said that he had "many families waiting to talk with you."

Fetterman (1998) recommends beginning with the "big net" approach in ethnographic research, accomplished through the second method for data collection, group interviewing. The boss walked me to the church, where I was greeted by several male members of the council in the foyer area. The boss walked me to the front of the church where 36 women and 2 men (out of 115 total colony population) sat in the pews. I first introduced myself to the group and my reason for being on the colony, established rapport, and then invited others to share their stories. The group interview lasted just under 4 hours. All members remained for the entire duration of the group interview except for one bereaved mother who left after 3 hours because she was in charge of meal preparation for the day.

The third mode of data collection included seven, unstructured, open-ended interviews with individuals and families, representing the deaths of ten children, from newborn to 19 years of age. Each interview lasted anywhere from 30 minutes to 6 hours. All of these interviews took place with bereaved mothers. Interview data were noted, recorded, and kept in the form of:

1. field notes;

2. memos;

3. public documents;

4. photographs; and

5. other artifacts, including mementos shared by the family members.

The fourth mode utilized unstructured, open-ended interviewing with three key leaders on the colony who included the colony boss, preacher, and an elder woman in the community. Finally, participant observation data were recorded each day in a journal using headers for essential materials, descriptive notes, and reflective notes that occurred in situ. In addition, data also included subsequent personal letters from participants.

\section{Data Analysis}

Data management was the first step toward analysis, and included reading through all the materials - field notes, memos, documents, photographs, and daily journals - before organizing the data based on code segments that best described patterned regularities in the data (Wolcott, 1994). Those segments were placed into a matrix that delineated five thematic categories:

1. details of the actual death experience;

2. emotional and physical reactions to the loss;

3. individual, familial, and communal response;

4. coping and rituals; and

5. spirituality category. 
Then came the interpretive processes of the culture-sharing group within their specific cultural context as well as within the larger context of scholarly evidence published on child death. To increase internal validity, I engaged in member checking, or respondent validation, a crucial step in establishing the credibility of the findings (Lincoln \& Guba, 1985), with the colony boss and one of the interviewees.

\section{RESULTS}

\section{Specific Description of the Culture-Sharing Group}

The specific colony studied is nestled in more than 5,000 acres of prairie farmland in South Dakota where each individual is "provided for equally and nothing is kept for personal gain" (Farm Manager, personal communication, June 27, 2010); this agrarian Hutterian colony flourishes with more than 23 families and a population of 115 people. Run by a church council of six members, this Schmiedeleut colony is one of five local colonies, one of which is the "mother colony," all within a 30-mile range. Statewide, there are 51 colonies in total and expanding. It is a place where both forgiveness and gratitude are constantly sought attributes, and the daily ritual of collective "prayer to keep the law of faith and good works inspired by God" is accomplished with "trembling and humility" (Farm Manager, personal communication, June 27, 2010).

As "strong advocates of education," there is a main school with a kindergarten located on the colony grounds where 36 children attend beginning at age 2 . The concept of prayer, peace, sharing are the "main lessons of school" (Farm Manager, personal communication, June 27, 2010). Colony members speak High German as their primary language, so English speaking, non-Hutterites from local school districts teach classes in English beginning at age 6. Children on the colony are said to have four mothers: their birth mother and three older women "who look after them and who specialize in prayer, song, and discipline" (Farm Manager, personal communication, June 27, 2010). These women are viewed as partners in child rearing by colony members, and their focus is to teach children about the "afterlife, forgiveness, and service." The terms "grandpa and grandma" are used often in many non-kin relationships. There is "zero tolerance" on the colony for the use of expletives, and each member is expected to act with integrity and respect for others. Adultery, theft, and petty crimes are virtually non-existent, and no one locks their home (Farm Manager, personal communication, June 27, 2010).

Beginning at age 15 , young men are inducted into a husbandry apprenticeship. At the same age, young women begin to learn practical skills such as knitting, sewing, cooking, and canning, "until every member finds his or her place of most usefulness" (Farm Manager, personal communication, June 27, 2010). Visits from guests, colony business, and meal times are communicated through a public address system. Meals are eaten together in one room, with men on one side 
and women on the other. Following lunch, each member returns home for a nap at 2:30 p.m. There is one landline phone that is housed in the home of the farm manager, and each member is allowed up to 10 minutes per day to use the phone. There are no computers, cellular phones, or other forms of social technology. Medical care, however, is sought outside the colony.

This colony has two large wind generators and it shares its electricity with the local rural power company. In addition to the farmland, there are several large gardens yielding produce for the colony's use including potatoes, onions, asparagus, and sweet corn. This colony has an extensive dairy cow farm, and organically raises hogs, turkeys, and chickens for market. Their domestic commodities are prolific, producing, for example, 70,000 turkeys in one year. The farm manager, or the "colony boss," oversees all matters social, economic, and agricultural, and often members seek his guidance, even about issues related to bereavement and loss. The preacher is the second key leader, and he manages all things spiritual.

The Hutterites on this colony attend church every day for 30-45 minutes, and for 1 hour or more on Sunday. There is no music in church; however, there is often acappella singing, praying, and reading of scripture and traditional Hutterite teachings. Children study both German and religion after school hours each day, and most adults are baptized at age 21 . They are sociopolitical pacifists who believe that "Christ commanded that we love God above all else and your neighbor as yourself" and "everything belongs to everyone" (Farm Manager, personal communication, June 30, 2010). These canons also manifest outside the colony. Several such examples of altruistic traditional acts include blood donation every 8 weeks and organ donation of their deceased loved ones in order to save a non-Hutterite life. Autopsies are exceedingly rare on the colony and only occur in "highly suspicious deaths." These decisions are "left to the family."

\section{FIVE THEMATIC CATEGORIES}

\section{Details of the Actual Death Experience}

I heard someone, a girl outside, scream. It was terrifying. And I felt a strong knowing that it was him, that something happened to him. I ran out of the house praying "dear God please help me" over and over. (Mother of a 10 -year-old boy who died in a farm accident)

Three families experienced the deaths of multiple children. One lost a stillborn baby in 1980 to unknown causes, and subsequently her 5-year-old son died as a result of a neuroblastoma. She described both children's deaths in detail, noting of her 5-year-old's death, though anticipated: "I thought I was prepared but it wasn't as I thought." Another mother experienced the stillbirth of her twin boys just 4 months prior to the study. She described holding and naming the babies, 
noting that "I couldn't have handled it if I didn't hold them." Another mother lost all four of her children in a fire 20 years earlier in 1990, stating that "I questioned God but I prayed." Her husband, she said, "was completely hysterical." He later died at age 53, an event she described as "even harder" than the deaths of her four children. Four other families lost a single child: one lost her 19-year-old son in a farm accident, noting he was her only boy of five children and that she was "still struggling"; another lost her 10-year-old son in a farm accident; and two others lost their children from terminal illnesses.

This theme was the first to emerge in every narrative, both in the group interview and in the one-on-one interviews. Participants seemed to want to tell their story repeatedly, working through the details and expressing, quite openly, their traumatic experiences.

\section{Emotional and Physical Reactions to the Loss}

I went through so much pain even though he died peacefully. Even today I cry thinking of it. I felt depressed. I tried Zoloft but it didn't help. There were many, many tears and even my other children suffered. (Mother of a toddler who died of cancer)

I have a lot of bad days. Occasionally, I have good days. But even on the good days I feel so sad underneath the smile and there is so much pain. . . . I think of them every single day. I will never forget them. (Mother of twins who were stillborn at 6 months gestation)

Each mother described psychological processes congruent with those that emerge in mainstream studies on parental bereavement, identifying specific emotional experiences such as guilt, denial, despair, and sadness (Cacciatore, DeFrain, Jones, \& Jones, 2008). They also expressed profound emotional reactions to their losses during both the group and individual interviews. One mother, whose 10-year-old son was "dragged under a tractor," said that she "collapsed" under the weight of the "shock and grief." She described the need to ride in the ambulance with her son, not wanting to leave him alone, noting that, "I had to be near him." Ten years later, she says she continues to "cry and miss him and feel the sadness." A mother who lost twin sons to early stillbirth talked about her pain being exacerbated by the "constant reminder" of her sister's twins, born around the same time her babies were due. At this point, she became very emotional and wept openly during the group interview. Another mother found herself withdrawing after her young child's death, and like many others described physical symptoms such as lethargy, headaches, nausea, and weight gain. Individual interviews affirmed these emotional and physiological symptoms.

Interestingly, during the course of the group interview not a single participant mentioned one salient emotion in current research on parental bereavement: anger. Thus, I inquired specifically about anger; however, the participants appeared nonplussed, many simultaneously declaring they had never experienced anger. 
During each subsequent individual interview I intentionally inquired, at the end of the interview, about anger. Each person again explicitly eschewed anger. Three mothers discussed how their surviving children, however, went through periods of "anger and rebellion" following the death of their siblings, and that the process was "hard on them" not only because of their own grief, but also as witnesses to their "mother's grief." Another thing I noted was that participants discussed having "nice dreams," rather than nightmares. Idiosyncratic posttraumatic stress symptoms, specifically avoidance, hypervigilance and startle, and intrusion, did not appear to be part of their current or past symptomatology. Only one mother, who had lost her four children in a house fire, described a brief period of nocturnal hyperarousal that endured for several days.

\section{Familial and Communal Response}

With the help of my husband and my family and a lot of colony support, I have made it. He was my only son, and it helps that so many people valued his place in the colony. (Mother of 19-year-old who died in a farming accident)

During the group interview, many colony members attended who did not directly lose a child. However, as mothers discussed their losses, other colony women collectively and openly mourned with them as they told their stories, reaching out to touch them on the back or on the hand. Some of the nonbereaved-parent participants remembered and spoke of details that several mothers had forgotten since the loss. I noted they were expressive, used the dead child's name, and obviously experienced their own grief as extended members of a larger family system. Participants openly discussed the ways that each family member responded differently to the death. Many mothers spoke of gender differences in mourning: "My husband and I grieved so differently." Others spoke of the struggles of surviving and subsequent children: "Our younger daughter always wants to visit him in the cemetery." The four older siblings of the twins who died in utero "took it very hard," and the mother felt as if she "had to comfort them, but I needed comforting." Some siblings did experience what the mothers identified as anger or rebellion, quickly quelled by social proscriptions of colony life. Mothers whose children died years earlier described how important it was to them that their subsequent children knew the story of their sibling who died: "Our children remember him and we keep him alive and part of our family." One mother who lost her four children in a fire noted that her husband "grieved more" than she did and that she "spoiled" her "next child" because of her losses.

Hospital bills and any other final expenses are paid through the common colony fund, and the mother and father of the child who died are "relieved from work duties" for as long as necessary. Most people are "held up" for 2 weeks then gradually resume their responsibilities as able, although "life is never the same." Fellow colony members and relatives appear "overwhelmingly 
supportive," "sympathetic," and "willing to listen." The bereaved are never alone unless they ask for solitude. Participants described an incontrovertible trust in one another, as they "eat together, laugh together, cry together, and pray together" from birth until death.

No participant mentioned the transgressions of others in their narratives. Nearly every participant, however, expressed gratitude repeatedly for the kindnesses of others, Hutterite and non-Hutterite, in the aftermath of their losses. Their focus often seemed to be on recognizing others' compassion: "At all times, someone was hugging me," "The doctor was so helpful and he knelt down in front of us and told us," "Everyone in our path was so caring," and "He told us with sad, caring eyes our son died."

\section{Coping and Rituals}

Everyone from miles and miles around came to his funeral, and my sisters and I talk about him all the time. We look at his photographs and we remember the things he said or did. Sometimes we laugh, sometimes we cry. But we do it together. (Mother of an 8-year-old who died of cancer)

Shared ritualization plays a key role in coping for grieving families on the colony. Funerals as last rites are a very important part of the Hutterite tradition. Caskets are made by the colony woodsmith, and each colony has its own cemetery where family members are often buried near one another. The deceased's body is kept in the family home until the evening wake. From 8:00 until 11:00 p.m., colony members attend a wake in the church. The body is then carried back to the family home, followed the next day by a "mostly open casket" funeral where every person "walks around the family of the dead" as a sign of support. The funerals of the dead are attended by Hutterites from all surrounding areas, usually between 400-600 people, who eat lunch together prior to the funeral. Only the colony minister speaks at the funeral and the eulogy is often brief, focusing on "what we are doing with our lives and ensuring we don't have unfinished business." Prior to burial, the family will have many opportunities to say goodbye: "We are given alone time with our dead ones." The headstones are designed by the family of the deceased and are often written in German. The funeral services of babies and young children, under age 5, are different from those of older children who die. "Fewer people attend" because "fewer people knew" the child. Every mother described how important it was to say goodbye: "I am so glad that I had that time with the twins. I cannot imagine where I'd be if I hadn 't."

Mementos were important to all the families. Both during the individual and group sessions, bereaved mothers shared photo albums, poetry, scrapbooks, and other tangible keepsakes documenting their child's life and death. One mother told the story of how painful it was for her as she watched her son's 8th grade class graduate, and they intentionally kept his photo on the wall with the five other graduating students. Another colony member mentioned it to her, acknowledging 
his absence, and the mother wept: "It means so much-those little times-when others remember him." The same mother modified their most recent family photograph to include her son's picture because she "couldn't bear the family photo without him." Parents describe such microritualistic mementos as: "memory books, special candles, angel bears, curio cabinet, and special poetry" that serve the purpose of "helping stay connected" to their child who died: "We have a lot of reminders of the twins in our house. It brings me comfort."

There is narrative evidence of posttraumatic growth in the data. The desire to discover meaning through helping others, both inside and outside the colony, was a common aspiration for many bereaved families. One family donated their young son's organs to three donors. She described the emotional process for her and her husband as they approached first the minister, then the doctor, and then the hospital with their decision. The mother currently corresponds with one of the donors who received a liver transplant and says that she lived "because of [him]." This young woman then went on to have a baby who was named after the young boy who died. Another woman donated because it is "what he would have wanted." Mothers described how they "get together and drink tea" and share their mementos with one another. This collective reprocessing appeared to serve as a type of bonding time between colony women where the "older grieving mothers comfort the newer grieving mothers" with song, and food, and prayer.

\section{Spirituality}

We put more into our spiritual life and our entire community revolves around our spiritual connection to God. When I drive down the road and see a beautiful crop, I thank God and see His hand in it. We pray morning and night, twice with each meal, and at church. We thank God all the time and we are very grateful for everything we have. We trust God's will because without God we have nothing. (Farm Manager)

Spirituality emerged as the most salient variable in the narratives of parentally bereaved Hutterite families, both individually and collectively, noting that "Faith in God is the most important to us" and "We survived because of the touch of God." Bereaved mothers acknowledged "God's goodness" through their struggles, even if "it still hurts." The mothers described having a "little questioning toward God," tempered by "faith that God has a plan for us, even if it's hard." The mothers seem firmly committed to faith in a reunion with their children, comforted that "they went to Heaven without sin." The Hutterites believe that "babies and children go straight to Heaven" because "who could be more innocent," and they "trust God's plan" even when it's "painful."

Forgiveness is a cornerstone principle of their theological culture. One family who lost their son when a fellow colony member inadvertently activated a piece of farm machinery approached the man and offered their forgiveness, 
assuring him it was not his fault and that "it was [their son's] time to die." While "some on the outside can't understand," the Hutterites collectively "accept and trust in God's will" unconditionally.

\section{Ex Post Facto}

As part of reciprocity, I brought about 25 copies of bibliotherapeutic materials specific to parental bereavement to the colony. Those items included psychoeducational brochures, bereaved parent newsletters, and grief specific books. Within minutes of offering them, the materials were taken by individuals who were both directly bereaved and indirectly bereaved. The ones who did not receive copies were palpably disappointed and in my field notes I wrote, "Hungry for information!" They asked me to send more, and I agreed. Several of the bereaved mothers sent thank you cards within the few months following data collection: "How do I begin to say thank you for hearing my story?"; "I hope you'll come again."; and, "The things you sent were so helpful for us, thank you."

In addition, 4 months following the conclusion of data collection, the colony boss contacted me seeking additional bibliotherapy materials for a family whose 8-year-old died in a farm accident in October. As a researcher and practitioner, it was apparent throughout my experience on the colony, and even months later, that leaders of the community recognize the unique pain of a family experiencing infant and child death, and they are willing to seek help from non-Hutterites to find help.

\section{DISCUSSION}

Previous literature suggests that "children who die young are envied for having avoided life's temptations and struggles" (Ingoldsby, 1999, p. 388) and that children's deaths are "prized" not "abhorred" in Hutterian society (Stephenson, 1983). Yet, the results of this study depict a more nuanced story. While no bereaved father's voice was recorded as it relates to infant or child death on the colony, the voices of mothers, both individually and collectively, suggest that infant and child death are exceedingly painful experiences for families. Despite their spiritual beliefs that "babies go straight to heaven" and that "most mothers accept that it was meant to be" (key leader, personal communication, July 1, 2010), the effects of child death "never go away." During both group and individual interviews, mothers openly mourned for their dead babies and children, expressing emotional experiences ranging from sadness, guilt, and disbelief to "a little questioning of God" and even social withdrawal. Though anger was not expressed by participants, it is possible that this emotion may be constrained by sociocultural norms. Thus, its disavowal within the colony may result in sublimation or some other means of psychopathological expression that is, perhaps, not easily recognizable. 
It is interesting to note that previous research suggests, however, a very low prevalence of psychopathology, including schizophrenia and anxiety, among the Hutterites when compared to non-Hutterite populations (Eaton \& Weil, 1955; Torrey, 1995), and suicide is exceedingly rare for colony members (Stephenson, 1997). Researchers attribute this to high cohesion and low dispersion. Eaton and Weil (1955) estimated that more than $97 \%$ of Hutterites had never experienced mental illness other than depressive symptoms, a condition they know as anfechtung. Anfechtung symptoms include weeping, difficulty sleeping, loss of appetite, and seeking solitude. And, most importantly, "as soon as the behavior associated with anfechtung begins to be displayed, the [colony] enfolds the suffering individual within a set of support individuals and practices" that help them overcome their angst (Stephenson, 1997, p. 111) through empathy and compassion. Because those with anfechtung are not stigmatized, some assert that the colony qualifies as a therapeutic community which can "ameliorate the serious consequences of mental disorders or disability" (p. 110). Yet, importantly, colony members seem to differentiate anfechtung from bereavement, despite the fact that the losses may have occurred years ago. Mourning is perceived as a justified act of love while anfechtung derives from endogenous, not reactive, sadness (Farm manager, personal communication, July 1, 2010). Nevertheless, whether the emotional despair is reactive or endogenous, the community responds mindfully, intentionally, and with compassion.

This shared processing often manifests through rituals. And, these acts have a distinct purpose in social bonding and thus are not "empty performances." Rather, they are imbued with "meaning, symbolism, and moral consequences" and bind members together in a common moral language (Sosis, 2003, p. 98). These shared practices create a very different environment for processing grief in the wake of a child's death, one in which the death is openly acknowledged and felt by the entire community. This may be because on the colony "Hutterites have a specific system for taking care of every member from birth to death" (Freese, 1994, p. 55). The bereaved are never left alone unless they specifically ask for solitude, and there is genuine willingness among colony members to be present and share with another's sorrow. Furthermore, they are given as much time off from their colony responsibilities as needed, in contrast to mainstream culture, which has a socially dictated mourning period and often rigid bereavement leave policies (Pratt, 1981).

While it is one thing for the Hutterites to believe that children are assured a "place in heaven upon death" and to find a measure of consolation in that belief, it is quite another to say that the deaths of children are "prized," which disregards the depth of grief and suffering of the bereaved parents and family. Despite their isolation from mainstream culture, the Hutterian experiences of traumatic infant and child death and their expressions of loss are similar to those of non-Hutterites. The emotional cadence following the death of a child appears to be a universal part of the human experience. 


\section{LIMITATIONS}

This study is cross sectional, and no causal conclusions can be drawn. Additionally, some of the deaths occurred years prior to the study, and thus are subject to memory bias. The study occurred in one Hutterite community and thus may not represent the total population of Hutterite colonies globally. Finally, because of the reluctance of Hutterite males to interact with non-Hutterite females on very personal matters (in this case, the primary investigator), no fathers' voices were recorded in the study; thus, only the mothers' perspectives were actually recorded in first person. Despite the limitations, this study illuminates many important, previously undiscovered data with regards to infant and child death among the Hutterite population, and offers some interesting insights to the larger community about the process of shared mourning, forgiveness, gratitude, and spirituality.

\section{CONCLUSION}

Grief can be expressed differently, individually and collectively, in traditional societies versus modern societies. In traditional societies, usually small villages, there is a greater degree of cohesion and familiarity as everyone knows and relies on everyone else in a "dense human sphere" (Stephenson, 1997, p. 116). Demonstrations of empathic support are expressed and perceived in more tangible ways and daily rituals, such as shared meals, stories, and spiritual worship. A loss within a small community — and the resultant emotional anguish — may be easier to acknowledge openly. By contrast, in contemporary, urban society, intimate social circles are likely to be smaller, more fragmented, spanning several locations. Consequently, loss and mourning can be a more isolating experience for the bereaved. While "private" grief is experienced by only a small circle of individuals directly impacted by the loss, "shared" grief is where the death is recognized and mourned by the entire community (Walter, 2007). There is also narrative evidence that, for the Hutterites, focusing on the numinous aspects of loss seem to foster posttraumatic growth.

In sum, the Hutterites' spiritual beliefs play a significant role in their daily lives, thus they also influence their experiences of grief. Several examples of this may be the seeming and remarkable absence of both anger and PTSD symptomatology. Additionally, their profuse and contemplative expression of gratitude, even for small gestures of kindness, was a salient theme in this study. And the tangible communal trust during periods of mourning is influenced by their unmitigated trust in God over their losses. Hutterian colonies exist in a unique intersection of traditionalism and modernity, an agrarian culture amidst a modern, geographically mobile, and increasingly urbanized society. While this study suggests that parental grief is no less anguishing than in mainstream culture, the Hutterite community's response to child death is markedly open in their support and sharing of the mourning experience. 
This cultural portrait of the Hutterites illustrates the ways in which community, social support, and spirituality help the bereaved process their loss. It is imperative for clinicians to be cognizant of the role of spirituality and faith in the course of grief. While the dominant society may be quick to dismiss their way of life as "quaint," the ways in which these bereaved families speak of their deceased children and the comfort and strength they derive from their faith demonstrate the healing power of collective compassion, shared ritualization, and the "touch of God."

\section{REFERENCES}

Bogdan, R., \& Biklen, S. (1992). Qualitative research for education: An introduction to theory and methods. Boston: Allyn and Bacon.

Cacciatore, J. (2009). Appropriate bereavement practice after the death of a Native American child. Families in Society, 90(1), 46-50.

Cacciatore, J. (2010). Stillbirth: Clinical recommendations for care in the era of evidencebased medicine. Clinical Obstetrics and Gynecology, 53(3), 691-699.

Cacciatore, J., DeFrain, J., Jones, K., \& Jones, H. (2008). The couple and the death of a baby. Journal of Family Social Work, 11(4), 351-370.

Creswell, J. W. (2007). Qualitative inquiry and research design (2nd ed.). Thousand Oaks, CA: Sage.

Eaton, J., \& Weil, R. (1955). Culture and mental disorders. Glencoe, IL: Free Press.

Fetterman, D. (1998). Ethnography step-by-step (2nd ed.). Thousand Oaks, CA: Sage.

Freese, B. (1994). All things in common. Successful Farming, 92(10), 54-61.

Hatfield, E., Rapson, R. L., \& Le, Y. L. (in press). Primitive emotional contagion: Recent research. In J. Decety \& W. Ickes (Eds.), The social neuroscience of empathy. Boston, MA: MIT Press.

Hemer, S. R. (2010). Grief as social experience: Death and bereavement in Lihir, Papua New Guinea. Australian Journal of Anthropology, 21, 281-297.

Hofer, S. (1998). The Hutterites: Lives and images of a communal people. Saskatoon, Saskatchewan: Hofer Publishers.

Hostetler, J. (1974). Hutterite society. Baltimore, MD: Johns Hopkins University Press.

Hutterian Brethren Schmiedeleut Conference. (2006). Hutterite history. Hutterian Brethren Schmiedeleut Conference: Decker Colony, Shoal Lake, Manitoba. Retrieved 10/24/2010 from http://www.hutterites.org/HutteriteHistory/index.htm

Ingoldsby, B. (1999). The Hutterite family in transition. Paper presented at the Communal Studies Association annual meeting, St. George, Utah.

Ingoldsby, B. (2001). The Hutterite family in transition. Journal of Comparative Family Studies, 32(3), 377-392.

Janzen, R. (2005). The Hutterites and the Bruderhof: The relationship between an old order religious society and a twentieth-century communal group. Mennonite Quarterly Review, 4, 506-541.

Janzen, R., \& Stanton, M. (2010). The Hutterites in North America. Baltimore, MD: Johns Hopkins University Press.

Larsen, U., \& Vaupel, J. W. (1993). Hutterite fecundability by age and parity: Strategies for frailty modeling of event histories. Demography, 30(1), 81-102. 
Lincoln, Y. S., \& Guba, E. G. (1985) Naturalistic inquiry. Beverly Hills, CA: Sage.

Morgan, K. (1983). Mortality changes in the Hutterite Brethren of Alberta and Saskatchewan, Canada. Human Biology, 55(1), 89-99.

Packull, W. O. (1999). Hutterite beginnings: Communitarian experiments during the Reformation. Baltimore, MD: Johns Hopkins University Press.

Peter, K. A. (1987). The dynamics of Hutterite society. Edmonton, Alberta: University of Alberta Press.

Pratt, L. (1981). Business temporal norms and bereavement behavior. American Sociological Review, 46(3), 317-333.

Rhodes, R. (2009). Nightwatch: An inquiry into solitude. Intercourse, PA: Good Books.

Sosis, R. (2003). Why aren't we all Hutterites? Costly signaling theory and religious behavior. Human Nature, 14(2), 91-127.

Stahl, L. M. (2003). My Hutterite life. Helena, MT: Farcountry Press.

Stephenson, P. H. (1983). "He died too quick!": The process of dying in a Hutterian colony. Omega, 14(2), 127-134.

Stephenson, P. H. (1997). The Hutterites. In I. Al-Issa \& M. Tousignant (Eds.), Ethnicity, immigration, and psychopathology. New York: Plenum Press.

Torrey, E. F. (1995). Prevalence of psychosis among the Hutterites. Schizophrenia Research, 16(2), 167-170.

Van Maanen, J. (1988). Tales of the field: On the ethnography. Chicago, IL: University of Chicago Press.

Walter, T. (2007). Modern grief, postmodern grief. International Review of Sociology, 17, 123-134.

Wolcott, H. F. (1994). Transforming qualitative data: Description, analysis, and interpretation. Thousand Oaks, CA: Sage.

Direct reprint requests to:

Joanne Cacciatore, Ph.D., FT, LMSW

Arizona State University

School of Social Work

411 N. Central Ave., Suite 800

Phoenix, AZ 85004-0689

e-mail: Joanne.Cacciatore@asu.edu 